Article

\title{
Inclusion Complexes of Melphalan with Gemini-Conjugated $\beta$-Cyclodextrin: Physicochemical Properties and Chemotherapeutic Efficacy in In-Vitro Tumor Models
}

\author{
Waleed Mohammed-Saeid ${ }^{1,2}$, Abdalla H Karoyo ${ }^{3}\left(\mathbb{D}\right.$, , Ronald E Verrall $^{3}$, Lee D Wilson ${ }^{3}(\mathbb{D}$ \\ and Ildiko Badea ${ }^{1, *}$ \\ 1 Drug Discovery and Development Research Group, College of Pharmacy and Nutrition, \\ University of Saskatchewan, 107 Wiggins Rd, Saskatoon, SK S7N 5E5, Canada \\ 2 College of Pharmacy, Taibah University, Medina 42353, Saudi Arabia \\ 3 Department of Chemistry, University of Saskatchewan, 110 Science Place, Saskatoon, SK S7N 5C9, Canada \\ * Correspondence: ildiko.badea@usask.ca; Tel.: +1-306-966-6349
}

Received: 12 July 2019; Accepted: 10 August 2019; Published: 22 August 2019

\begin{abstract}
C D)$ has been widely explored as an excipient for pharmaceuticals and nutraceuticals as it forms stable host-guest inclusion complexes and enhances the solubility of poorly soluble active agents. To enhance intracellular drug delivery, $\beta C D$ was chemically conjugated to an 18-carbon chain cationic gemini surfactant which undergoes self-assembly to form nanoscale complexes. The novel gemini surfactant-modified $\beta C D$ carrier host (hereafter referred to as $18: 1 \beta C D g$ ) was designed to combine the solubilization and encapsulation capacity of the $\beta C D$ macrocycle and the cell-penetrating ability of the gemini surfactant conjugate. Melphalan (Mel), a chemotherapeutic agent for melanoma, was selected as a model for a poorly soluble drug. Characterization of the 18:1ßCDg-Mel host-guest complex was carried out using $1 \mathrm{D} / 2 \mathrm{D}{ }^{1} \mathrm{H}$ NMR spectroscopy and dynamic light scattering (DLS). The 1D/2D NMR spectral results indicated the formation of stable and well-defined 18:1 $\beta C D g-M e l$ inclusion complexes at the 2:1 host-guest mole ratio; whereas, host-drug interaction was attenuated at greater $18: 1 \beta C D g$ mole ratio due to hydrophobic aggregation that accounts for the reduced Mel solubility. The in vitro evaluations were performed using monolayer, 3D spheroid, and Mel-resistant melanoma cell lines. The 18:1ßCDg-Mel complex showed significant enhancement in the chemotherapeutic efficacy of Mel with 2-3-fold decrease in Mel half maximal inhibitory concentration $\left(\mathrm{IC}_{50}\right)$ values. The findings demonstrate the potential applicability of the $18: 1 \beta C D g$ delivery system as a safe and efficient carrier for a poorly soluble chemotherapeutic in melanoma therapy.
\end{abstract}

Keywords: cationic gemini surfactant; melphalan; inclusion complex; ROESY NMR spectroscopy; 3D spheroid; drug-resistant melanoma

\section{Introduction}

Melanoma, the malignant cancer of melanocytes, is the most aggressive form of skin cancer which causes the most skin-cancer related deaths [1]. According to the World Health Organization (WHO), over 132,000 new cases of melanoma are diagnosed annually [2]. In its early stages, melanoma can be treated by surgical incision with high survival rate. In the stage of in-transit metastases, in which the metastases are $>2 \mathrm{~cm}$ from the primary lesion but within the nodal basin, the response to local and systemic therapeutic options is moderate with 5-year survival of $32.8 \%$ [3,4]. However, advanced metastatic melanoma shows limited response to current therapeutic options with very low survival 
rate of less than $5 \%$ over 5 years [5]. Systemic chemotherapy is the first-line option for most patients with metastatic melanoma.

Melphalan (Mel) (Figure 1a) is used regionally as an adjunctive therapy for in-transit metastatic melanoma [6]. The lipophilic nature of Mel requires the use of a co-solvent (e.g., propylene glycol) for parenteral administration. Propylene glycol is known to cause toxicity that includes nephrotoxicity, cardiac arrhythmia, and metabolic acidosis [7]. As a result, the use of Mel in melanoma therapy is limited to isolated limb perfusion/infusion which is an invasive method that requires special medical care [6]. Therefore, attempts to improve the solubility and stability of Mel were conducted by either chemical modification of the molecule or by engineering novel drug delivery systems, such as nano-systems [8-11]. A nanoscale drug delivery system has several advantages, it can: (1) improve solubility of poorly soluble drugs, (2) enhance chemical/biological stability, (3) improve pharmacokinetic profile and biodistribution, (4) increase tumor-specific uptake (passive targeting), (5) minimize drug resistance, (6) achieve drug controlled release, and (7) afford delivery of multiple drug components $[12,13]$. Our strategy is to create delivery systems that could improve the therapeutic use of Mel addressing both issues of solubility and biological activity at the same time. Cyclodextrins (CDs) form stable host-guest complexes with a variety of organic and inorganic molecules and have been widely employed as versatile carriers for poorly soluble drugs [14]. CDs (Figure 1b,c) are naturally occurring cyclic oligosaccharides consisting of $6(\alpha \mathrm{CD}), 7(\beta C D)$, or $8(\gamma \mathrm{CD}) \alpha$-D-glucopyranose units linked by $(\alpha-1,4)$ glycosidic bonds [15]. CDs form a truncated cone with a toroidal structure (Figure 1c) in which the hydroxyl groups of glucopyranose units reside at the narrow (primary) and wide (secondary) tori of the $\mathrm{CD}$ annular structure. The $\mathrm{CD}$ macrocycle has a hydrophilic outer surface and lipophilic inner cavity that is capable of forming noncovalent inclusion complexes with a large variety of guest molecules [16]. Capitalizing on the ability of the CDs to form host-guest inclusion complexes, such systems have been used in pharmaceutical formulations to increase the apparent water solubility of poorly soluble drugs so as to improve their bioavailability. In addition, CDs and its derivatives serve to provide: (1) enhanced drug stability (thermal, photosensitivity, and chemical), (2) reduced drug mucosal irritation, (3) reduced drug resistance, and (4) controlled release of the drug [17,18]. Several synthetic strategies have been employed to engineer CD-based carriers with enhanced pharmaceutical properties along with reduced systemic toxicity [18]. For example, the introduction of bulky derivatives can limit the formation of intramolecular hydrogen bonding, consequently enhancing the aqueous solubility of CDs while improving their inclusion capacity [14]. Luke et al. reported a 35-fold increase in aqueous solubility for a sulfobutyl-ether- $\beta$-cyclodextrin (SEB- $\beta-C D)$ derivative relative to native $\beta C D$ [19]. In addition to chemical derivatization, $C D$ s have been chemically conjugated to a variety of functional moieties (i.e., polymers, lipids, and peptides) to create biofunctional and supramolecular complexes [20,21]. For instance, several amphiphilic moieties have been conjugated to CDs to create self-assembling supramolecular structures with improved drug loading capacity and enhanced cellular uptake [22-25].

In the present work, we evaluate a novel $\beta C D$-based carrier modified with an unsaturated 18-carbon chain gemini surfactant conjugate, herein referred to as $18: 1 \beta C D g$ (Figure $1 \mathrm{~d}$ ), as a potential advanced drug delivery system for Mel in melanoma therapy. The objectives of the current study are generally two-fold: 1) to synthetically engineer a novel CD-based carrier for Mel with improved therapeutic efficiency and low carrier-cellular toxicity, and 2) to characterize the structure of the host-guest interaction between the carrier and drug. The host-guest complex of the 18:1ßCDg-Mel system was investigated using $1 \mathrm{D} / 2 \mathrm{D}{ }^{1} \mathrm{H}$ NMR spectroscopy in aqueous solution. NMR results herein show the formation of well-defined carrier-drug inclusion complexes. We previously reported a cationic gemini surfactant $\beta C D$ conjugate with 12 -carbon chain $(12 \beta C D g)$ for the delivery of a poorly soluble drugs including curcumin analogs [26-28] and Mel in a melanoma cell line model [29]. The $12 \beta C D g$-Mel complex significantly improved the efficiency of Mel drug and showed no intrinsic toxicity as it did not alter the cellular death triggered by Mel [29]. However, the stability of the formed host-drug inclusion complex and the efficiency of the produced $12 \beta \mathrm{CDg}$-Mel system were limited 
due to the self-inclusion/self-assembly of the terminal alkyl chains of the carrier agent within the $\beta C D$ cavity [27-29]. Therefore, the newly developed delivery system herein using a cationic gemini surfactant- $\beta C D$ conjugate with 18 -carbon tail $(18: 1 \beta C D g)$ is anticipated to overcome these limitations. The in vitro efficiency of the 18:1 $\beta C D g$-Mel complex using monolayer, 3D spheroid, and Mel-resistant melanoma cell lines demonstrates the potential applicability of the 18:1 $\beta C D$ delivery system as a safe and efficient carrier for poorly soluble chemotherapeutic in melanoma therapy. This study is anticipated to provide a greater understanding of the structure-function relationship of $18: 1 \beta C D g$ as a carrier agent for poorly soluble drug with optimal therapeutic properties.

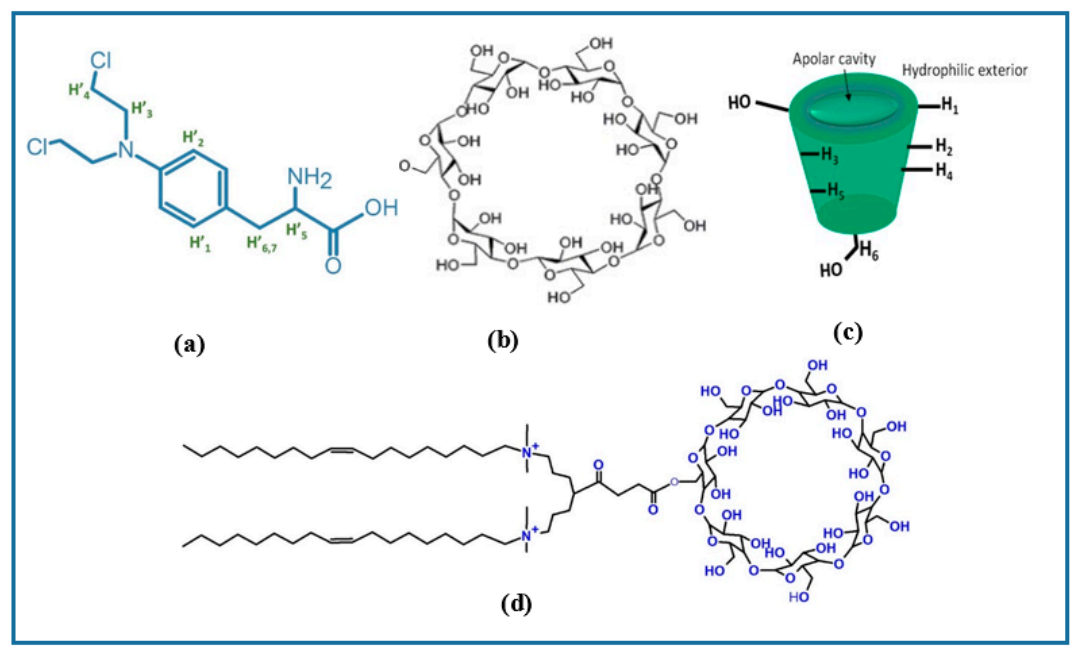

Figure 1. Chemical structures of (a) Melphalan (Mel), (b) $\beta$-Cyclodextrin $(\beta C D)$ macrocycle, $(\mathbf{c}) \beta C D$ toroidal structure showing cavity and external protons, and (d) 18:1 $\beta C D g$ host (carrier).

\section{Material and Methods}

\subsection{Preparation of Inclusion Complexes}

Melphalan (Mel) and $\beta$-Cyclodextrin $(\beta C D)$ were purchased from Sigma-Aldrich (Oakville, ON, Canada). Synthesis and characterization of 18:1-7N $\beta C D-18: 1$ gemini surfactant [18:1 $\beta C D g$ ] was described elsewhere [26,30]. Figure 1 shows the chemical structures of Mel, $\beta C D$, and 18:1 $\beta C D g$. For physicochemical characterization, the complexes of Mel with $\beta C D$ or 18:1 $\beta C D g$ were prepared in different carrier-to-drug molar ratios (1:1, 2:1, 3:1, and 5:1). A stock solution of Mel (1 mg/mL) was prepared in acidified ethanol $(0.1 \% \mathrm{HCl})$. Stock solutions of $\beta C D$ and $18: 1 \beta C D g$ were prepared in Milli-Q water at $10 \mathrm{mM}$ concentration. An appropriate volume of Mel solution was mixed with $\beta C D$ and an aqueous $18: 1 \beta \mathrm{CDg}$ dispersion to yield the required carrier-to-drug molar ratios. Formulations were frozen at $-80^{\circ} \mathrm{C}$ for $2 \mathrm{~h}$ and transferred to a cascade freeze dryer (Labconco, Kansas City, MO, USA) at $-80^{\circ} \mathrm{C}$ and $0.03 \mathrm{mBar}$ vacuum and lyophilized for $24 \mathrm{~h}$. The lyophilized formulations were rehydrated in water (or in deuterium oxide for ${ }^{1} \mathrm{H}$ NMR and 1D/2D ROESY experiments) and shaken in the orbital shaker for $1 \mathrm{~h}$ at room temperature prior to evaluation.

\subsection{Physicochemical Characterization}

\subsubsection{Size and Zeta Potential Measurements}

Eight hundred microliters of rehydrated formulations were transferred into a special cuvette (DTS1061, Malvern Instruments, Worcestershire, UK) for size distribution and zeta potential measurements using a Zetasizer Nano ZS instrument (Malvern Instruments, Worcestershire, UK). Each sample was measured in triplicate and the results are expressed as an average \pm standard deviation (SD), where $n=3$ with a corresponding polydispersity index (PDI) value. 


\subsubsection{NMR Spectroscopy}

1D/2D ${ }^{1} \mathrm{H}$ ROESY NMR spectra in solution were recorded on a $500 \mathrm{MHz}$ 3-channel Bruker Avance spectrometer in $\mathrm{D}_{2} \mathrm{O}$ at $298 \mathrm{~K}$. Chemical shifts $(\delta)$ are reported in ppm with respect to trimethylsilane (TMS; $\delta 0.0 \mathrm{ppm}$ ) as external standard. ${ }^{1} \mathrm{H} 1 \mathrm{D}$ spectra were obtained with water solvent suppression, a $2 \mathrm{~s}$ recycle delay, and a $90^{\circ}$ pulse length $(10 \mu \mathrm{s})$. 2D ROESY NMR spectra were obtained at variable parameters which were optimized as follows: spin-lock time of $350 \mathrm{~ms}$, recycle delay of $3 \mathrm{~s}$ with 8 scans and $1 \mathrm{k}$ data points. Complexation-induced chemical shift (CIS) values were calculated as $\Delta \delta=\delta_{\text {free }}-\delta_{\text {complex }}$.

\subsection{In Vitro Evaluation}

Human malignant melanoma (A375) cell line (ATCC ${ }^{\circledR}{ }^{\circledR}$ CRL-1619 ${ }^{\mathrm{TM}}$, Cedarlane, Burlington, ON, Canada) was cultured in Dulbecco's modified Eagle's medium (DMEM) supplemented with $10 \%$ fetal bovine serum and $1 \%$ antibiotic and incubated at $37^{\circ} \mathrm{C}$ under an atmosphere of $5 \% \mathrm{CO}_{2} / 95 \%$ air. For all experiments, culturing conditions and passage numbers were kept constant.

\subsubsection{Determination of Half Maximal Inhibitory Concentration $\left(\mathrm{IC}_{50}\right)$ in Monolayer Melanoma Cell Culture}

A375 cell lines were seeded at a density of $1 \times 10^{4}$ cells/well and incubated for $24 \mathrm{~h}$. Cells were treated with serial concentrations of $\operatorname{Mel}(32 \mathrm{nM}$ to $250 \mu \mathrm{M})$, either alone or as 18:1ßCDg-Mel complexes at a 2:1 molar ratio, and $18: 1 \beta \mathrm{CDg}$ alone $(64 \mathrm{nM}$ to $500 \mu \mathrm{M})$ in quadruplicate. After $24 \mathrm{~h}$ of treatment, cell viability was assessed using MTT (3-(4,5-dimethylthiazolyl-2)-2,5-diphenyltetrazolium bromide) (Sigma-Aldrich, Markham, ON, Canada) assay. The supplemented DMEM containing the treatment was removed from the wells and replaced with $0.5 \mathrm{mg} / \mathrm{mL}$ MTT in supplemented media and incubated at $37^{\circ} \mathrm{C}$ for $3 \mathrm{~h}$. The supernatant was removed and each well washed with phosphate-buffered saline (PBS). The formed formazan was dissolved in DMSO. Plates were incubated for $10 \mathrm{~min}$ at $37^{\circ} \mathrm{C}$. Absorbance was measured at $580 \mathrm{~nm}$ using BioTek microplate reader (Bio-Tek Instruments, Winooski, VT, USA). The half maximal inhibitory concentration $\left(\mathrm{IC}_{50}\right)$ was determined by calculating the fraction of dead cells and plotting the data with a 4-parameter curve generated by GEN5 software from BioTek.

\subsubsection{In Vitro Efficiency in Spheroid Melanoma Cell}

To evaluate the efficiency of developed formulations in three-dimensional cell culture, melanoma cells (A375) were cultured at a density of $1 \times 10^{4}$ cells/well in 96-well spheroid microplate (Corning Inc., Tewksbury, MA, USA). Cells were incubated at $37^{\circ} \mathrm{C}$ under an atmosphere of $5 \% \mathrm{CO}_{2} / 95 \%$ air for $48 \mathrm{~h}$ prior to treatment with Mel and 18:1 $\beta \mathrm{CDg}$-Mel complexes. After $48 \mathrm{~h}$, cells were treated twice (2nd treatment $24 \mathrm{~h}$ after the first) with Mel alone and with 18:1 $\beta \mathrm{CDg}$-Mel complexes at 2:1 molar ratio with final Mel concentrations of 30 and $80 \mu \mathrm{M}$ in quadruplicate. The CytoTox-ONE Homogeneous Membrane Integrity Assay (Promega Corporation, Madison, WI, USA) was used to determine the lactate dehydrogenase (LDH) activity $12 \mathrm{~h}$ after the 2 nd treatment. An equal volume of CytoTox-ONE ${ }^{\mathrm{TM}}$ Reagent $(100 \mu \mathrm{L})$ was added to cell culture medium in each well and incubated at $23{ }^{\circ} \mathrm{C}$ for $10 \mathrm{~min}$. Fifty microliters of stop solution was added to each well and fluorescence was measured using an excitation wavelength of $560 \mathrm{~nm}$ and an emission wavelength of $590 \mathrm{~nm}$ by using a BioTek microplate reader. Maximum LDH release was used as a control by adding $2 \mu \mathrm{L}$ of lysis solution to 4 wells of nontreated cells. \% cell toxicity was calculated as follows:

$$
\% \text { Cell Toxicity }=\frac{(\text { Experimental }- \text { Culture Medium Background })}{(\text { Maximum LDH Release }- \text { Culture Medium Background })}
$$




\subsubsection{In Vitro Efficiency in Mel-Resistant Melanoma Cell Lines}

Mel-resistant melanoma cultures were created by using A375 cell line, as described previously [29]. In brief, A375 cells cultured in $25 \mathrm{~cm}^{2}$ tissue culture flasks and treated with increasing concentrations of Mel from $100 \mathrm{nM}$ to $60 \mu \mathrm{M}$ over 9 weeks to induce drug resistance. The Mel-resistant cells were seeded at a density of $1.5 \times 10^{4}$ cells/well in 96-well plate and incubated for $24 \mathrm{~h}$. After the incubation period, cells were treated with Mel alone and with 18:1 $\beta \mathrm{CDg}-\mathrm{Mel}$ complexes at 2:1 molar ratio with final Mel concentrations of 30 and $80 \mu \mathrm{M}$ in quadruplicate. The MTT assay, as described above, was used to determine \% cell toxicity (compared to nontreated cells).

\subsection{Statistical Analysis}

Statistical analyses were performed using SPSS software (v 24.0). Independent $t$-test and one-way analysis of variance (Bonferroni's post hoc tests) were used. Significant differences were considered at $P<0.05$ level.

\section{Results and Discussion}

\subsection{Physicochemical Characterization}

\subsubsection{H NMR and 1D/2D ROESY}

Several spectroscopy methods (NMR, circular dichroism, and FT-IR) have been utilized to characterize the structure of host-guest inclusion complexes, along with X-ray diffractometry (XRD) and mass spectrometry (MS) [31,32]. Solution state NMR spectroscopy is a powerful tool for elucidating the molecular level structure and host/guest stoichiometry by analyzing the complexation-induced shifts (CIS). In particular, two-dimensional NMR affords an understanding of the through-space dipolar interactions and inclusion geometry of the guest within the $\beta C D$ cavity $[27,33,34]$. In 2D ROESY NMR, the nuclear Överhauser effect (NOE also ROE) is employed to elucidate the noncovalent interactions between nuclei that reside in close spatial proximity $(\sim 5 \AA)[35,36]$. Although 2D NMR ROESY cross-correlations are related to $\mathrm{NOE}$, other correlations may arise due to chemical and conformational (rotational) exchanges [37].

In the current work, $1 \mathrm{D} / 2 \mathrm{D}{ }^{1} \mathrm{H}$ ROESY NMR was employed to elucidate the structure of the 18:1 $\beta \mathrm{CDg}$ and its complexes with Mel. The ${ }^{1} \mathrm{H}$ signals in Figure 2 were assigned according to previous reports $[27,38]$ and the simulated spectra (cf. Figures S1 and S2 Supporting information). Starting with the $18: 1 \beta C D g$ carrier molecule, evidence of the formation of the gemini surfactant-grafted $\beta C D$ is shown by the substantial broadening of the $\beta C D$ resonance lines $(\sim 3.0-4.5 \mathrm{ppm})$ relative to the native $\beta C D$ (Figure 2a,c, respectively), along with the emergence of the gemini surfactant signals at $\delta \sim 0.5-1.0 \mathrm{ppm}$ (Figure 2c). Similar line broadening effects were reported previously for grafted $\beta C D$-based hosts in $\mathrm{D}_{2} \mathrm{O}$ [37]. The downfield shifts $(\Delta \delta \sim 0.04-0.10 \mathrm{ppm}$, Table 1$)$ of the external and framework protons of the $18: 1 \beta \mathrm{CDg}$ (i.e., $\mathrm{H}_{1}, \mathrm{H}_{4}$, and $\mathrm{H}_{6}$; cf. Figure $1 \mathrm{~b}$ ) indicate an induced conformational change of the $\beta C D$ macrocycle upon grafting. The internal cavity protons $\mathrm{H}_{3}$ and $\mathrm{H}_{5}$ of the $\beta C D$ moiety of the $18: 1 \beta C D g$ carrier (Figure 2 highlighted area II) are characterized by upfield shifts ( -0.03 and -0.08 ppm; cf. Table 1$)$ that indicate a possible inter- or intramolecular inclusion of part of the gemini surfactant moiety (cf. Figure 2c), consistent with shielding effects [38]. The alkenic signals of the gemini surfactant $\sim 5.4 \mathrm{ppm}$ (Figure 2 highlighted area I) are characterized by substantial broadening and upfield shift indicating a change of conformation and/or environment upon drug complexation as described above. 
Table 1. Complexation-induced chemical shift (CIS) data of the host ( $\beta C D$ and $18: 1 \beta C D g)$ and its complexes with Melphalan. The CIS values (in brackets) were calculated as $\Delta \delta=\delta_{\text {complex }}-\delta_{\text {free }}$, where negative and positive values represent shielding (upfield) and deshielding (downfield) effects, respectively. ${ }^{*}$ Chemical shift values are difficult to decipher.

\begin{tabular}{|c|c|c|c|c|c|c|c|}
\hline \multirow{2}{*}{ Host:Guest } & \multirow{2}{*}{ Ratio } & \multicolumn{6}{|c|}{${ }^{1} \mathbf{H}$ Nuclei } \\
\hline & & H1 & $\mathrm{H} 2$ & H3 & H4 & H5 & H6 \\
\hline$\beta C D$ & - & 4.98 & 3.56 & 3.87 & 3.49 & 3.77 & 3.76 \\
\hline$\beta C D: M e l$ & $2: 1$ & $\begin{array}{c}4.97 \\
(-0.01)\end{array}$ & $\begin{array}{c}3.57 \\
(0.01)\end{array}$ & $\begin{array}{c}3.85 \\
(-0.02)\end{array}$ & $\begin{array}{c}3.48 \\
(-0.01)\end{array}$ & $\begin{array}{c}3.70 \\
(-0.07)\end{array}$ & $\begin{array}{l}3.78 \text { * } \\
(0.02)\end{array}$ \\
\hline 18:1ßCDg & - & $\begin{array}{c}5.02 \\
(0.04)\end{array}$ & * & $\begin{array}{c}3.84 \\
(-0.03)\end{array}$ & $\begin{array}{l}3.59 * \\
(0.10)\end{array}$ & $\begin{array}{c}3.69 \\
(-0.08)\end{array}$ & $\begin{array}{c}3.83 \\
(0.07)\end{array}$ \\
\hline 18:1ßCDg:Mel & $1: 1$ & $\begin{array}{c}4.97 \\
(-0.01) \\
\end{array}$ & $\begin{array}{c}3.57 \\
(0.01) \\
\end{array}$ & $\begin{array}{c}3.80 \\
(-0.07) \\
\end{array}$ & $\begin{array}{c}3.50 \\
(0.01)\end{array}$ & $\begin{array}{c}3.61 \\
(-0.16)\end{array}$ & $\begin{array}{c}3.77 \\
(0.01) \\
\end{array}$ \\
\hline 18:1ßCDg:Mel & $2: 1$ & $\begin{array}{c}4.98 \\
(0.00)\end{array}$ & $\begin{array}{c}3.57 \\
(0.01)\end{array}$ & $\begin{array}{c}3.81 \\
(-0.06)\end{array}$ & $\begin{array}{c}3.52 \\
(0.03)\end{array}$ & $\begin{array}{c}3.62 \\
(-0.15)\end{array}$ & $\begin{array}{c}3.79 \\
(0.03)\end{array}$ \\
\hline 18:1ßCDg:Mel & $3: 1$ & $\begin{array}{c}4.99 \\
(0.01) \\
\end{array}$ & $\begin{array}{c}3.57 \\
(0.01) \\
\end{array}$ & $\begin{array}{c}3.81 \\
(-0.06) \\
\end{array}$ & $\begin{array}{c}3.52 \\
(0.03) \\
\end{array}$ & $\begin{array}{c}3.63 \\
(-0.14) \\
\end{array}$ & $\begin{array}{c}3.79 \\
(0.03) \\
\end{array}$ \\
\hline 18:1ßCDg:Mel & $5: 1$ & $\begin{array}{c}5.01 \\
(0.03)\end{array}$ & $\begin{array}{l}3.60 \text { * } \\
(0.04)\end{array}$ & $\begin{array}{c}3.83 \\
(-0.04)\end{array}$ & $\begin{array}{l}3.55 * \\
(0.06)\end{array}$ & $\begin{array}{c}3.67 \\
(-0.10)\end{array}$ & $\begin{array}{c}3.82 \\
(0.06)\end{array}$ \\
\hline
\end{tabular}

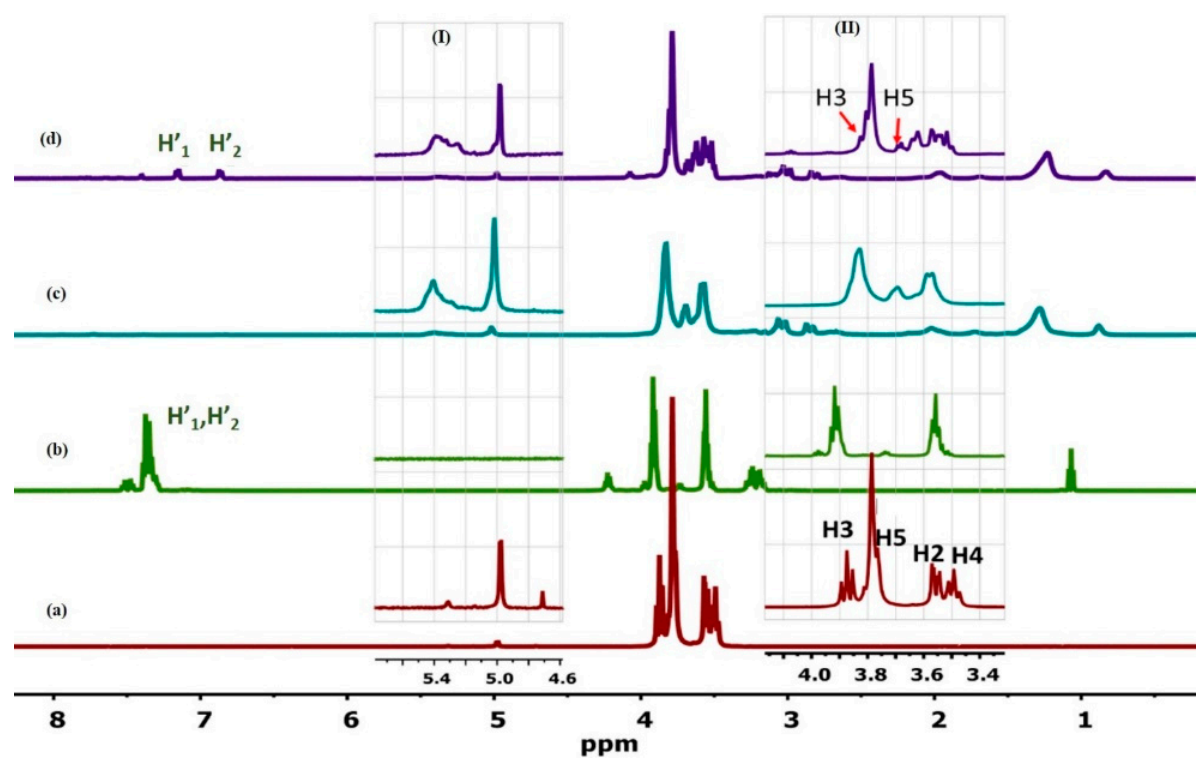

Figure 2. ${ }^{1} \mathrm{H}$ NMR spectra of (a) $\beta C D$, (b) Mel, (c) 18:1 $\beta C D g$, and (d) 18:1 $\beta C D g-M e l$ complex at 2:1 molar ratio obtained in $\mathrm{D}_{2} \mathrm{O}$ at $298 \mathrm{~K}$. The insets show enlarged resonance regions for the alkenic signal (H11) of the gemini (I) and $\beta C D$ signals (II). Some signals for the drug $\left(\mathrm{H}_{1}^{\prime}, \mathrm{H}_{2}^{\prime}\right)$ and the interior and exterior protons of $\beta C D$ are labeled.

In the case of the $18: 1 \beta C D g-M e l$, various host:guest complexes (1:1, 2:1, 3:1 and 5:1) were studied. The 1:1 and 2:1 18:1ßCDg-Mel complexes showed the most affected CIS values as listed in Table 2, indicating that the $18: 1 \beta C D g$ carrier forms $1: 1 / 2: 1$ stoichiometry with the drug. The $1 \mathrm{D}^{1} \mathrm{H}$ NMR spectrum of the 18:1 $\mathrm{CCDg}$-Mel complex at the 2:1 mole ratio is represented in Figure $2 \mathrm{~d}$ and reveals substantial shielding of the $\beta C D$ internal protons $(\sim 3.7-4.0 \mathrm{ppm})$ and the gemini surfactant ( 0.5-1.0 ppm) resonances. This provides evidence for the inclusion of the Mel within the cavity of the $\beta C D$ moiety with possible involvement of the gemini surfactant moiety. 
Table 2. Physiochemical properties (size and zeta potential) of different melphalan formulations. (-) indicates unmeasurable size or zeta potential. ${ }^{a}$ Results are an average of $\mathrm{n} \geq 3 \pm$ standard deviation (SD).

\begin{tabular}{|c|c|c|c|}
\hline Component $^{a}$ & $\begin{array}{c}\text { Size } \\
\mathrm{nm} \pm \mathrm{SD}\end{array}$ & PDI & $\begin{array}{c}\text { Zeta Potential } \\
\mathrm{mV} \pm \mathrm{SD}\end{array}$ \\
\hline Mel (1 mM) & - & - & - \\
\hline$\beta C D(2 \mathrm{mM})$ & - & - & - \\
\hline $18: 1 \beta C D g(2 \mathrm{mM})$ & $170 \pm 17$ & $0.329 \pm 0.047$ & $+14 \pm 3$ \\
\hline$\beta C D-M e l$ (2:1 mole ratio) & - & - & - \\
\hline 18:1ßCDg-Mel (2:1 mole ratio) & $160 \pm 15$ & $0.430 \pm 0.04$ & $+46 \pm 2$ \\
\hline
\end{tabular}

The $2 \mathrm{D}^{1} \mathrm{H}$ ROESY NMR spectra of 18:1 $\beta \mathrm{CDg}$ and its complexes with Mel are shown in Figures $3-5$. In Figure 3, the spectra of the unbound 18:1 $\beta C D g$ carrier displayed cross-peaks due to typical interactions between the backbone $\mathrm{H}_{1}$ proton of $\beta C D$ with the cavity interior (panel a). Furthermore, various cross-peaks are arising from intra-/intermolecular interactions of the 18:1 $\beta C D g$ carrier (Figure 3 , panel c). More recently, the self-inclusion of a 12-carbon chain gemini (12 $\beta C D g)$ within the $\beta C D$ cavity was reported [27]. In Figure 3, cross-peaks between the $\beta C D$ cavity and the alkyl chain of the gemini surfactant (highlighted area $b$ ) are relatively weak and characterized by positive correlations (green contours in Figure 3) due to possible conformation (rotational) and chemical exchanges [37]. The formation of host-guest inclusion complexes is expected to be thermodynamically more favorable for a saturated long hydrocarbon chain than shorter ones [39]. However, intermolecular aggregation of the gemini surfactant chain is anticipated to be more prominent in the case of $18: 1 \beta C D g$ due to the presence of the unsaturated bond that causes the tail to bend with less flexibility, which can reduce the self-inclusion of the tail region within the $\beta C D$ cavity.

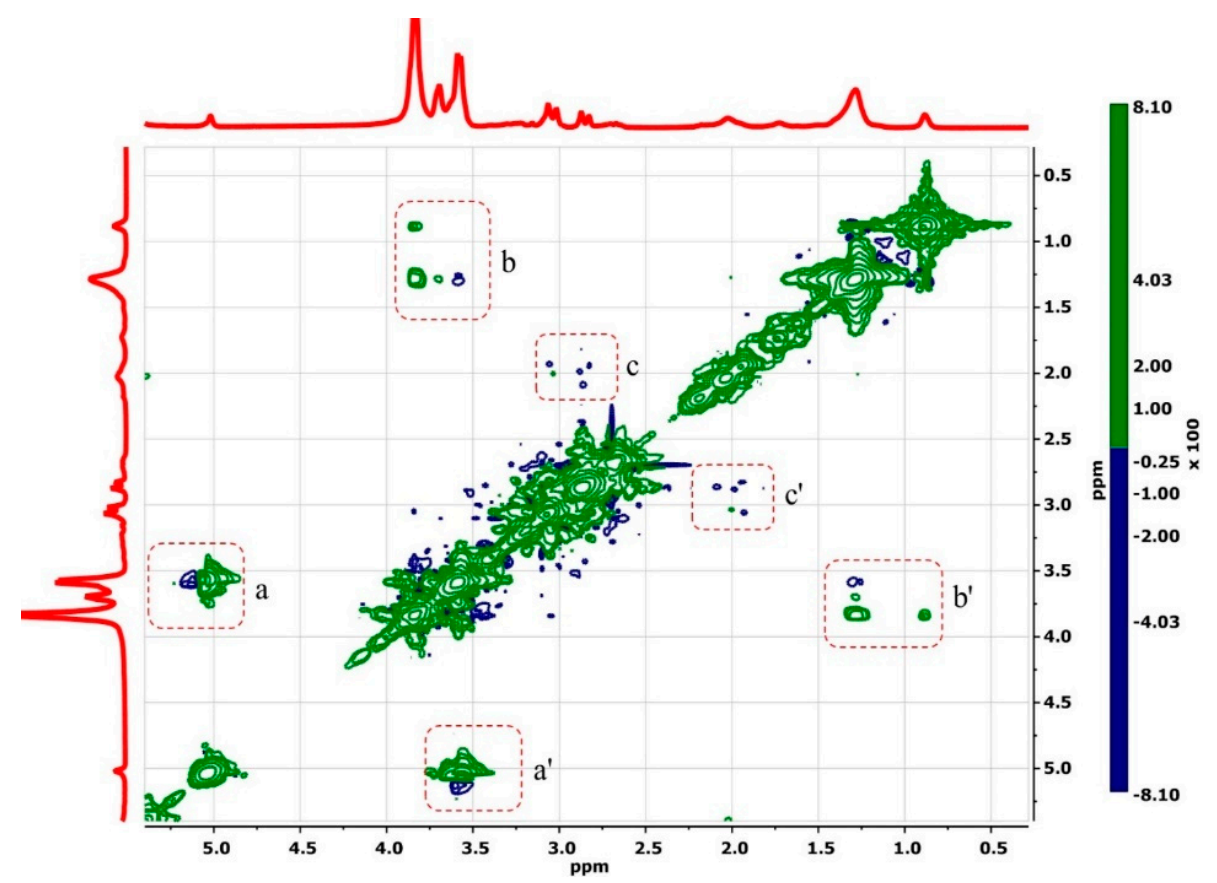

Figure 3. 2D ROESY ${ }^{1} \mathrm{H}$ NMR spectra of unbound $18: 1 \beta C D g$ in $\mathrm{D}_{2} \mathrm{O}$ and $295 \mathrm{~K}$. The inter- and intra-molecular cross-peaks are shown as highlighted areas $\mathbf{a}-\mathbf{c}$, and the bar to the right shows positive and negative correlations. 


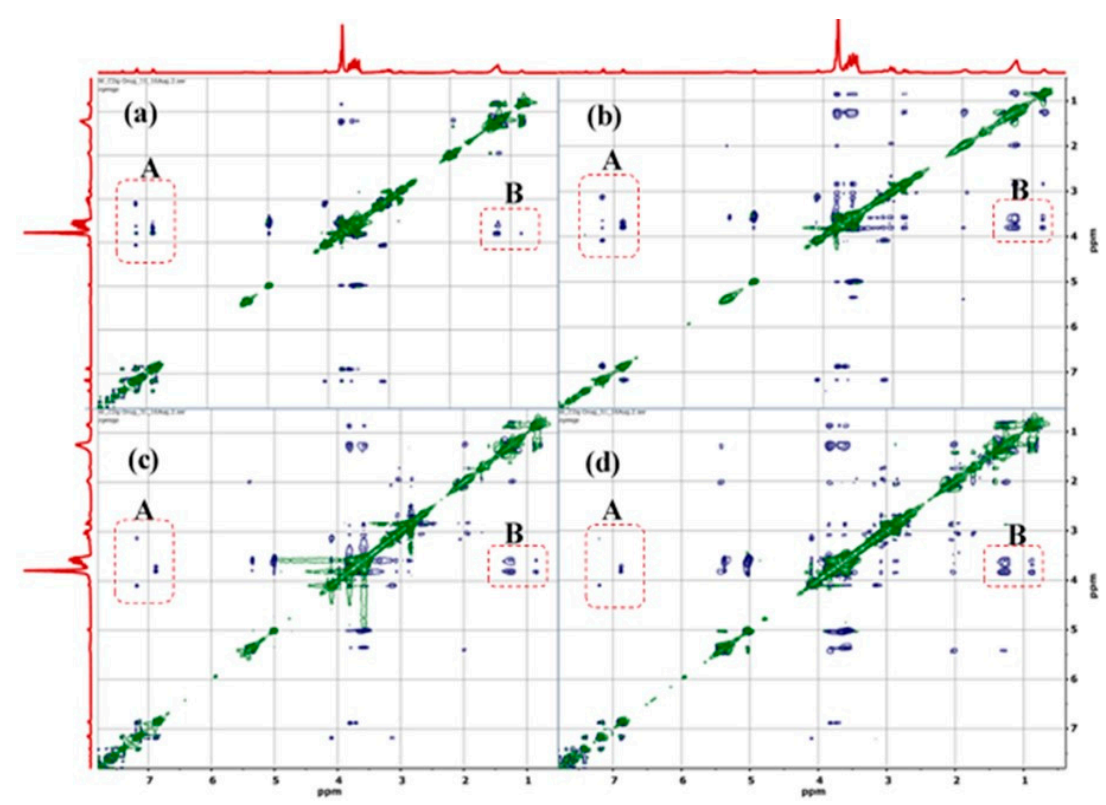

Figure 4. 2D ROESY ${ }^{1} \mathrm{H}$ NMR of the 18:1ßCDg-Mel complexes at (a) 1:1, (b) 2:1, (c) 3:1, and (d) 5:1 mole ratios. The cross-peaks for the $\beta C D-M e l$ and $\beta C D$-gemini surfactant interactions are shown in panels A and B. (A) interaction between $\mathrm{Mel}$ and $\beta \mathrm{CD}$ cavity and (B) gemini surfactant alkenic region with $\beta C D$ cavity.

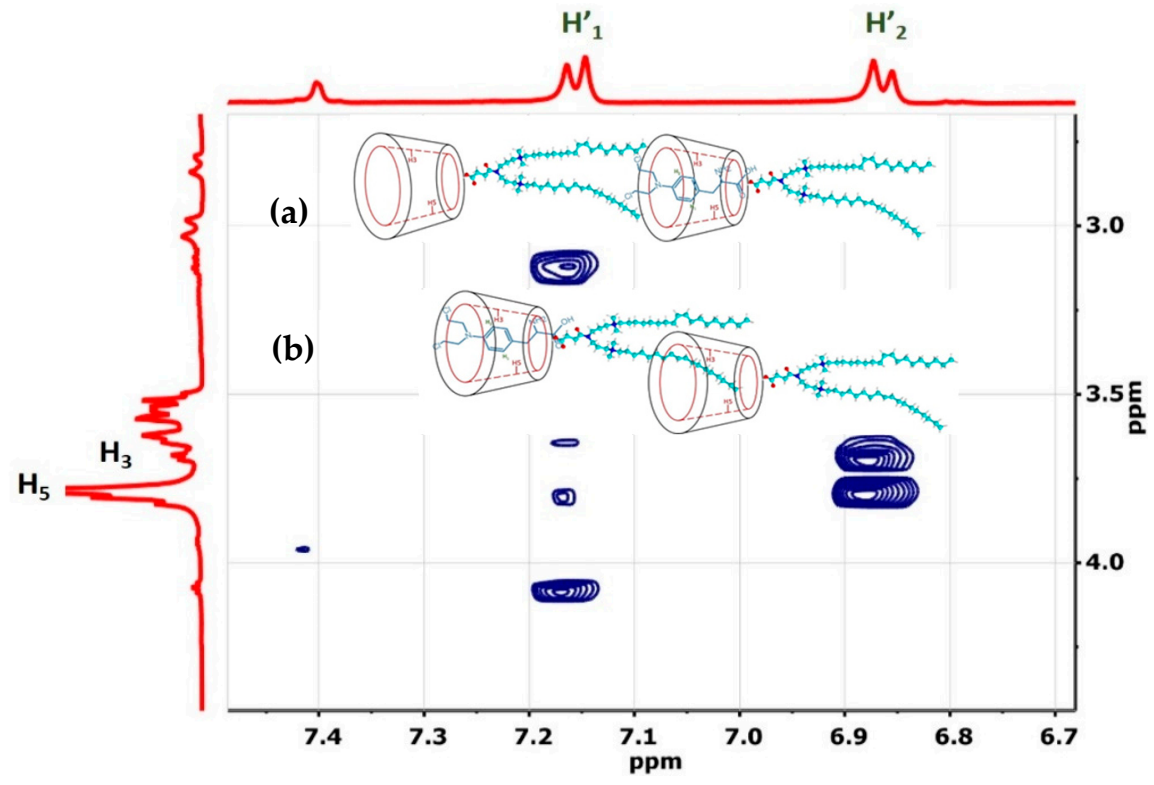

Figure 5. Expanded 2D ROESY ${ }^{1} \mathrm{H}$ NMR of the 18:1 $\beta C D$-Mel complex at 2:1 molar ratio in $\mathrm{D}_{2} \mathrm{O}$ at $295 \mathrm{~K}$. The possible geometries are depicted in the insets.

The relative comparison of the 2D ROESY spectra of the complexes of $18: 1 \beta C D g$ with Mel at various carrier:drug mole ratios (1:1, 2:1, 3:1, and 5:1) were used to further support the effect of stoichiometry on maximum solubility (Figure 4). According to the 2D ROESY spectra in Figure 4, the increased carrier-drug interactions at the 1:1 and 2:1 mole ratios are evidenced by the intense cross-peaks and suggest optimal solubilizing conditions for the drug, more so at the 2:1 mole ratio due to the much greater intensity. It is noteworthy that the interaction between the gemini surfactant and the $\beta C D$ moiety of the carrier in the presence of the Mel drug as a co-guest illustrates the importance of "cooperativity" in the host-guest inclusion complex. Evidence of cooperative association was reported recently for other $\beta C D$-based complexes $[37,40]$. In the present study, the "cooperative interaction" 
only occurred when Mel was added to the $18: 1 \beta C D g$. The foregoing solubility results inferred from the 2D NMR results agree with the CIS data herein (Table 1) and with solubility evaluation results reported previously using mass spectrometry [41]. The ${ }^{1} \mathrm{H}$ NMR CIS data in Table 1 provide evidence of destabilization of the carrier-drug inclusion complex due to hydrophobic effects and conformational motility of the $18: 1 \beta C D g$ at higher carrier loading, as indicated by the downfield shifts of the $\beta C D$ extracavity (or framework) nuclei (i.e., $\mathrm{H}_{1}, \mathrm{H}_{6}$, and $\mathrm{H}_{4}$ ). The efficiency of $18: 1 \beta C D g$ to increase the aqueous solubility of Mel was evaluated using mass spectrometry, where the highest aqueous solubility was determined at the 2:1 host-guest mole ratio [41]. Increasing the 18:1ßCDg-Mel mole ratios to 3:1 and 5:1 caused significant reduction in Mel solubility, consistent with the attenuated $\beta C D-M e l$ signals at the expense of the $\beta C D$-gemini surfactant signals for these systems (cf. Figure $4 c, d$ ). The foregoing discussion suggests increased interaction of the gemini surfactant moiety with the $\beta C D$ cavity at higher host ratio, whereas an alternate geometry involves one $18: 1 \beta C D g$ unit interacting with another 18:1 $\beta C D g$ unit inter-molecularly in a rotaxane-like fashion (cf. Scheme 1). The growing interactions between the gemini surfactant moiety at the alkenic region ( 5.4 ppm; Figure 4$)$ with the $\beta C D$ interior/exterior protons at the higher host ratios indicates a possible intermolecular aggregation of the gemini surfactant around the $\beta C D$ and further support the rotaxane-like structure depicted in Scheme 1 . These proposed structures are further supported by the shielding and deshielding CIS trends of the external and internal $\beta C D$ resonances, respectively (cf. Table 1 ). It is noteworthy to mention that the increased gemini surfactant- $\beta C D$ interaction at the $3: 1$ and $5: 1$ mole ratios of $18: 1 \beta C D g-M e l$ correlate with the limited solubility of the drug at these conditions (Scheme 1c).

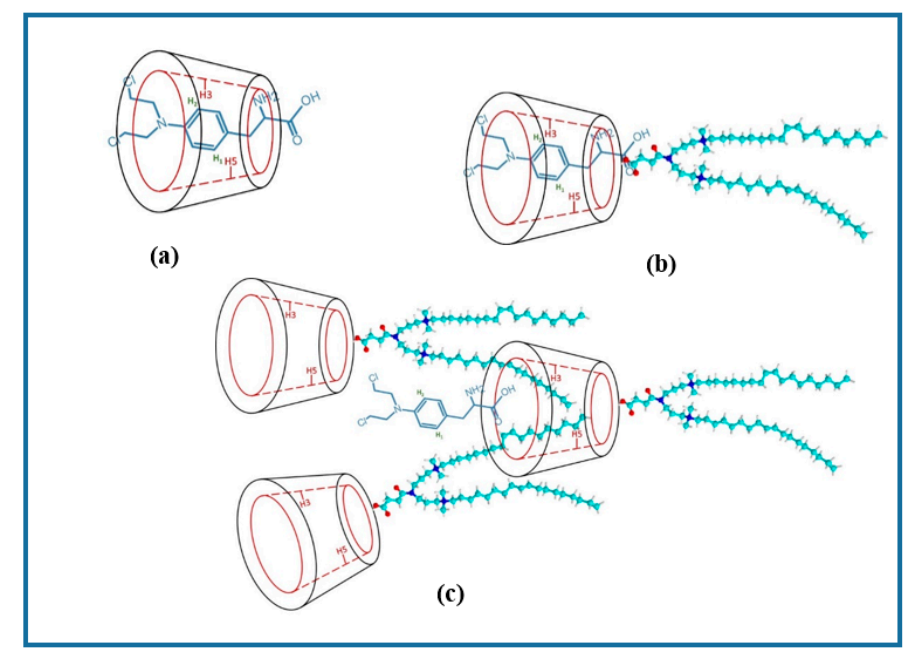

Scheme 1. Schematic presentation of the possible inclusion geometry of the Mel and gemini surfactant;

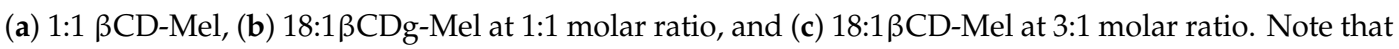
other possible geometries are possible and also the structures are not drawn to scale.

The 2D NMR results for the 2:1 18:1 $\beta C D g-M e l$ complex are shown as an expanded plot in Figure 5 and reveals NOE correlations due to interactions between the internal cavity of the $\beta C D$ moiety $\left(\mathrm{H}_{3}, \mathrm{H}_{5}\right)$ and the aromatic moiety of the drug at the $\mathrm{H}_{1}^{\prime}$ and $\mathrm{H}_{2}^{\prime}$ positions (cf. Figures $1 \mathrm{a}$ and 5). These results provide unequivocal evidence for the formation of the 18:1ßCDg-Mel complexes with well-defined binding and geometry that are consistent with the $1 \mathrm{D}^{1} \mathrm{H}$ CIS data. The more intense cross-peaks at $\mathrm{H} 5$ compared to $\mathrm{H} 3$ in Figure 5 suggests that Mel is directionally encapsulated within the $\beta C D$ cavity of the $18: 1 \beta C D g$ carrier, as depicted in Figure 5 (see insets). Similar geometry was deduced from the inclusion complex of Mel with pure $\beta C D$ according to 2D ROESY NMR results of the $\beta C D-M e l$ complex (cf. Figure S3).

Higuchi and Connors described an analytical approach to study the $\mathrm{CD} /$ drug solubility relation known as the phase-solubility method (Figure S4) [42]. This method examines the effect of a solubilizer ( $\mathrm{CD}$ or ligand) on the drug being solubilized (substrate). The phase-solubility relationship describes 
only the solubilizing effect of the $\mathrm{CD}$ on the drug molecule but not the actual formation of inclusion complexes. Based on the phase-solubility diagram of Higuchi and Connors, the solubility evaluation results reported previously using flow-injection mass spectrometry of $18: 1 \beta \mathrm{CDg}-\mathrm{Mel}$ [41] and the NMR results discussed herein, we propose that the relationship between the solubility of Mel and the concentration of the host $(18: 1 \beta C D g)$ follows either $A_{N}$ or $A_{-}-B_{S}$-type model. $A_{N}$-type model indicates the formation of a host-drug soluble complex with negatively deviating isotherms, whereas the A-BS-type indicates the formation of a complex with limited solubility [43]. $\beta C D$-drug complexes usually follow a B-type model as a result of the limited aqueous solubility of $\beta C D(1.85 \mathrm{~g} / 100 \mathrm{~mL})$. On the other hand, 18:1 $\beta C D g$ exhibits behavior characteristic of both $\beta C D$ and cationic gemini surfactant (amorphous molecule). The solubilization effect of $18: 1 \beta C D g$ is combination of formation of host-guest inclusion complex and the association complex formation that involve moieties that lie in the extracavity region of the $18: 1 \beta C D g$ (i.e., the gemini alkyl chain) as shown by the $2 \mathrm{D}$ NMR results for the 2:1 18:1ßCDg-Mel (Figures 4 and 5).

\subsubsection{Size and Zeta Potential}

Size of the carrier-drug complex can determine their route of administration and can affect stability, cellular uptake, biodistribution, toxicity, and clearance pathway [44-46]. For instance, optimal endocytosis requires particle size of the nanoparticles to be within the range of 100-200 $\mathrm{nm}$ [47]. In the current work, the particle size was measured for the 2:1 18:1ßCDg-Mel complex with size of approximately $160 \mathrm{~nm}$ (Table 2). Similarly, the 18:1 $\beta C D g$ carrier possesses an average size of ca. $170 \mathrm{~nm}$ characteristic of nanoparticles. At identical concentration conditions, $\beta C D-M e l$ complex and unbound $\beta C D$ failed to form particles with measurable particle sizes (Table 2). In a previous report, much

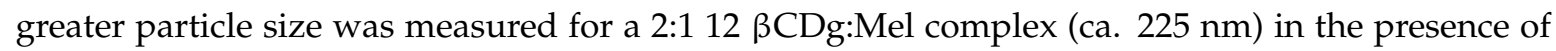
$0.5 \%$ methylcellulose as a suspending agent [29]. In the current work, the reported particle size of 18:1 $\beta C D g-M e l$ complex was measured in an aqueous medium without the need of a suspending agent and no visible precipitation was observed even after $24 \mathrm{~h}$. It is hypothesized that the replacement of saturated 12-carbon tails with unsaturated 18-carbon alkyl tails in the case of $18: 1 \beta C D g$ results in the formation of a stable inclusion complex.

Aside from particle size, the surface charge of a system can affect the physiochemical stability and biological behavior of carrier-drug formulations [48]. In Table 2, the zeta potential ( $\zeta$ ) data reveals much larger positive charge $(\zeta=46 \mathrm{mV})$ for the 18:1ßCDg-Mel complex compared to the uncomplexed $18: 1 \beta C D g$ carrier $(\zeta=14 \mathrm{mV})$. This effect can be explained by the difference in the measured $\mathrm{pH}$ values between the complex ( $\mathrm{pH} 2.8$ ) and the 18:1 $\beta C D g$ aqueous dispersion ( $\mathrm{pH}$ 4.7). Low acidic $\mathrm{pH}$ can lead to the protonation of melphalan, causing more positive $\zeta$-values [49].

\subsection{In Vitro Evaluation}

The in vitro activity of 18:1 $\beta C D g-M e l$ complex, optimized at the 2:1 mole ratio, was evaluated in different melanoma cell line models. The in vitro studies were performed to evaluate the ability of the carrier to: (1) enhance the efficiency of Mel in standard monolayer cell lines; (2) enhance the penetration of the Mel in 3D melanoma tissue culture; (3) overcome drug resistance in Mel-resistant cells.

A standard monolayer A375 cell line was used to determine the $\mathrm{IC}_{50}$ of Mel (cf. Table 3, Figure S5). The concentration of Mel required to induce cell death in the presence of $18: 1 \beta C D g$ carrier at the 2:1 (18:1 $\beta C D g-M e l)$ molar ratio was significantly lower with $\mathrm{IC}_{50}$ values of $27 \pm 1 \mu \mathrm{M}$ compared to Melalone with $\mathrm{IC}_{50}=98 \pm 1 \mu \mathrm{M}(P<0.05)$. Additionally, the $\mathrm{IC}_{50}$ value for the unbound carrier 18:1 $\beta \mathrm{CDg}$ was $\sim 89 \mu \mathrm{M}$. These results indicate that the 18:1ßCDg-Mel complex can significantly improve the efficiency of Mel with low carrier-specific toxicity of the cells. Recently, we reported that $\beta C D$-gemini system did not alter the cell death pathway induced by Mel, as shown by apoptosis and cell cycle analyses, indicating that the $\beta C D$-modified gemini surfactant bears no intrinsic toxicity to the cells [29]. 
Table 3. The $50 \%$ of inhibitory concentration $\left(\mathrm{IC}_{50}\right)$ of: [A] Mel-alone, [B] 18:1ßCDg alone, and [C] 18:1 $\beta \mathrm{CDg}$-Mel complexes at 2:1 molar ratio. $\mathrm{IC}_{50}$ determined in $\mathrm{A} 375$ monolayer cell lines by using MTT (3-(4,5-dimethylthiazolyl-2)-2,5-diphenyltetrazolium bromide) assay. IC S0 $_{50}$ was established by calculating the fraction of dead cells and plotting the data with a 4-parameter curve. $N=3 \pm \mathrm{SD}$.

\begin{tabular}{ccc}
\hline & Treatment & IC $_{\mathbf{5 0}}$ \\
\hline$[\mathrm{A}]$ & Mel & $98 \pm 1 \mu \mathrm{M}$ \\
{$[\mathrm{B}]$} & $18: 1 \beta \mathrm{CDg}$ & $89 \pm 2 \mu \mathrm{M}$ \\
{$[\mathrm{C}]$} & $18: 1 \beta \mathrm{CDg}-\mathrm{Mel}[2: 1$ molar ratio] & $27 \pm 1 \mu \mathrm{M}$ \\
\hline
\end{tabular}

To mimic the complex three-dimensional (3D) architecture of a solid tumor and to investigate the cell penetration ability of the $\beta C D$-modified gemini surfactant and hence the improvement in the drug permeability, a spheroid melanoma cell culture was created. Treatment of spheroid melanoma cell culture with $30 \mu \mathrm{M}$ 18:1 $\beta \mathrm{CDg}$-Mel complexes at Mel final concentration of $30 \mu \mathrm{M}$ (the approximate $\mathrm{IC}_{50}$ value in monolayer culture) caused $10 \%$ cell death, a three-fold increase in cell toxicity compared to Mel alone (cf. Figure 6). These results are based on the differences in $\mathrm{IC}_{50}$ values for Mel $(98 \mu \mathrm{M})$ and 18:1ßCDg-Mel $(27 \mu \mathrm{M})$ in monolayer A375 cell lines (cf. Table 3). Similarly, treatment of spheroid melanoma cell culture at greater Mel final concentration of $80 \mu \mathrm{M}$ (recapitulating the $\mathrm{IC}_{50}$ value of naked Mel in monolayer) showed $24 \%$ cell toxicity with $18: 1 \beta C D g-M e l$ complexes, compared to $14 \%$ for Mel-alone at the same conditions (Figure 6). While cell toxicity for 18:1 $\beta \mathrm{CDg}$-Mel complexes (at both 30 and $80 \mu \mathrm{M}$ ) are lower than cell death in A375 monolayer cell lines, the results are encouraging for future formulation development upon accounting for the higher complexity of the spheroid cell culture and smaller direct contact area with the drug dispersed in the cell culture medium compared to monolayer cultures. Nevertheless, formulating Mel with 18:1ßCDg caused a significant increase in the cytotoxicity of the drug at both concentrations. In our previous work, $12 \beta C D g$ did not improve the delivery of Mel in the tumor spheroids of A375 cells as no such difference were found between the $\mathrm{IC}_{50}$ values between Mel-alone and the Mel-12 $\beta \mathrm{CDg}$ formulation [29]. Thus, we hypothesize that the 18:1 $\beta C D g$, with unsaturated 18:1 tail, forms more favorable inclusion complexes with Mel than the $12 \beta C D g$ with 12-carbon alkyl tail. This may be attributed to the combined effect of a more prominent inclusion binding along with secondary interactions due to association of the non-included C18:1 gemini chain that resides in the interstitial region of $18: 1 \beta C D g$, as described in the NMR results (Scheme 1).

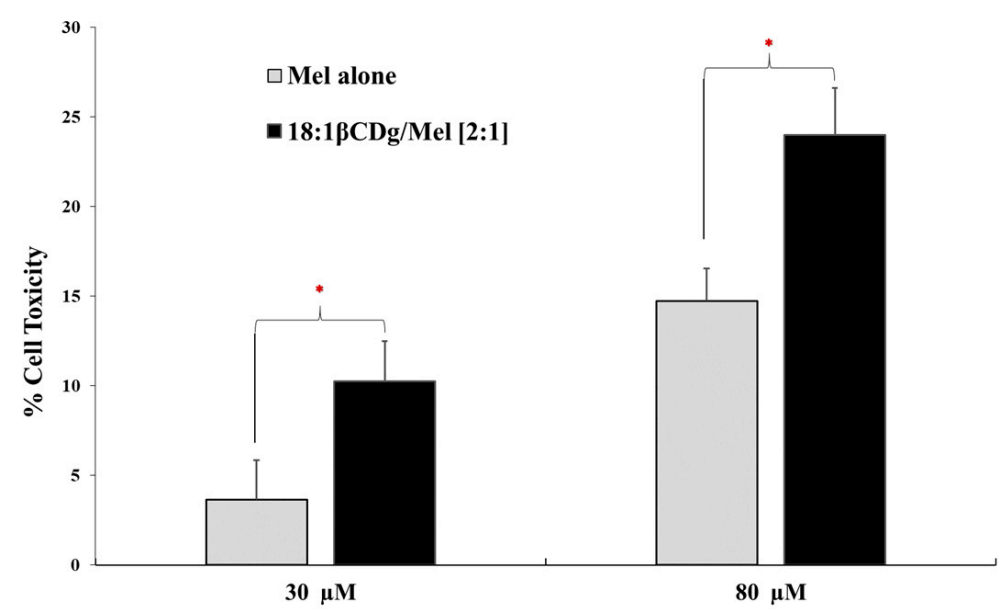

Figure 6. Cytotoxic efficiency of the Mel-alone and 18:1 $\beta$ CDg-Mel complexes (at 2:1 molar ratio) in 3D spheroid A375 melanoma cells. A375 cells were seeded at $1 \times 10^{4}$ cells/well in Corning ${ }^{\circledR}$ spheroid 96-well microplates and treated twice ( $24 \mathrm{~h}$ and $36 \mathrm{~h}$ after seeding) with Mel-alone and 18:1ßCDg-Mel complexes with final Mel concentrations of $30 \mu \mathrm{M}$ and $80 \mu \mathrm{M}$. Cell toxicity was reported as lactate dehydrogenase (LDH) activity. $N=3 \pm \mathrm{SD} *$ indicates significance $(P<0.05)$. 
Advanced drug delivery systems can provide a potential avenue to overcome drug resistance by enhancing the bioavailability of the drug target at the tumor site. This can be achieved by shielding the drug molecule via complex formation to minimize its efflux from the cell [50]. Previously, we reported that formulating Mel with $12 \beta C D g$ significantly improved the efficiency of the drug in Mel-resistant A375, whereas Mel alone showed minimum cell death at the same concentration, in line with the anticipated effect [29]. In the current work, we evaluated the capability of newly designed $\beta C D$-modified gemini surfactant $(18: 1 \beta C D g)$ to enhance the cytotoxic action of melphalan in Mel-resistant cultures (Figure 7). The Mel-resistant A375 cells showed low cell toxicity toward melphalan even at the highest concentration that was evaluated here ( $500 \mu \mathrm{M}$ of melphalan). Therefore, we used 30 and $80 \mu \mathrm{M}$ melphalan based on the known $\mathrm{IC}_{50}$ values of melphalan and the corresponding $\mathrm{IC}_{50}$ values of 18:1 $\beta \mathrm{CDg}$ alone in a standard monolayer cell culture assay (Table 3, Figure S5). Treating the Mel-resistant A375 melanoma cells with Mel-alone at 30 and $80 \mu \mathrm{M}$ caused low cell death $(4 \%$ and $27 \%$, respectively). However, after treating the Mel-resistant cells with 18:1 $\beta \mathrm{CDg}$-Mel complexes at final Mel concentration of 30 and $80 \mu \mathrm{M}$, a significant recovery of the activity was observed (46 and $76 \%$ cell death, respectively), as shown in Figure 7 . These results suggest that the 18:1 $\beta C D g$ delivery system was able to overcome the apparent drug resistance and enhance the treatment efficacy.

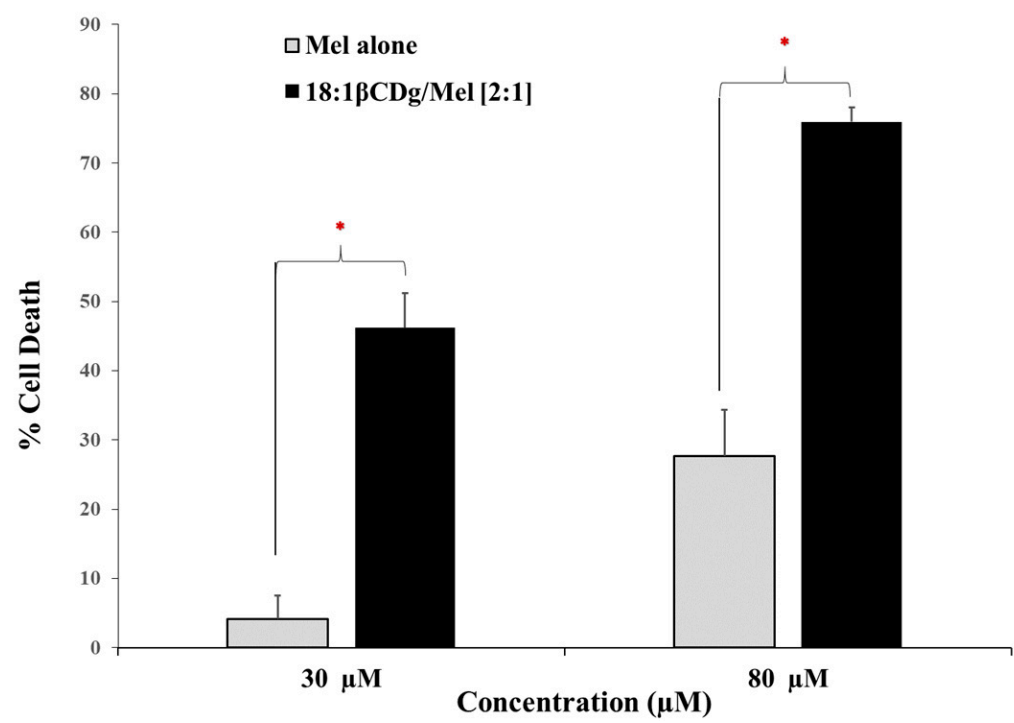

Figure 7. Cytotoxic efficiency of the Mel-alone and 18:1ßCDg-Mel complexes (at 2:1 molar ratio) in Mel-resistant A375 melanoma cells. A375 cells were seeded $1.5 \times 104$ cells/well in 96-well plate and after $24 \mathrm{~h}$ treated with Mel-alone and 18:1 $\mathrm{CD}$ g-Mel complexes with final Mel concentrations of $30 \mu \mathrm{M}$ and $80 \mu \mathrm{M}$. Cell death was reported as using MTT assay in comparison with nontreated cells. $N=3 \pm \mathrm{SD}$ * indicates significant $(P<0.05)$.

\section{Conclusions}

In this work, a novel carrier based on derivatization of $\beta C D$ with an unsaturated 18-carbon chain gemini surfactant conjugate $(18: 1 \beta C D g)$ was characterized and its potential as an advanced drug delivery system for Melphalan (Mel) drug in melanoma therapy was evaluated. The $18: 1 \beta C D g$ carrier and its complexes with Mel drug were characterized using 1D/2D NMR spectroscopy, along with the measurement of particle and zeta potential in aqueous solution. The $18: 1 \beta C D g$ carrier improves the solubility of Mel through formation of favorable inclusion complexes at the 2:1 mole ratio, as supported by 1D CIS data and 2D ROESY NMR results. The inclusion of Mel involves a well-defined geometry where the drug is directionally encapsulated within the internal apolar cavity of the $\beta C D$ carrier system, according to 2D ROESY NMR results. The self-inclusion of the terminal part of the gemini alkyl chain within the $\beta C D$ cavity cannot be ruled out especially at equimolar carrier/drug ratios. However, these effects are minimized at carrier mole ratios $>1: 1$ due to hydrophobic aggregation of the carrier chains. 
The measured particle sizes of the unbound 18:1ßCDg carrier (ca. $170 \mathrm{~nm}$ ) and the 2:1 carrier: drug complex $(160 \mathrm{~nm})$ are within nanoparticle size limits $(100-200 \mathrm{~nm})$. Thus, the 18:1 $\beta C D g$ carrier affords optimum stability, cellular uptake, biodistribution, toxicity, and clearance pathway of the reported formulation. As well, the in vitro evaluations of the optimized 18:1 $\beta C D g-M e l$ formulation in the presence of various melanoma models (i.e., monolayer, 3D spheroid, and Mel-resistant melanoma cells) resulted in significantly improved cytotoxic efficiency of the Mel in all cases. We are envisioning future studies to elucidate the pathways of cell penetration and of mechanism overcoming drug resistance of the 18:1ßCDg-drug complexes. This knowledge will enable us to further optimize the structure that aims to improve efficiency and increase penetration ability into spheroids.

Supplementary Materials: The following are available online at http://www.mdpi.com/1999-4923/11/9/427/s1, Figure S1. Predicted ${ }^{1} \mathrm{H}$ NMR spectra of Melphalan. Spectra was created using nmrdb online tool (www.nmrdb.org). Figure S2. Predicted ${ }^{1} \mathrm{H}$ NMR spectra of 18:1 gemini surfactant. Spectra was created using nmrdb online tool (www.nmrdb.org). Figure S3. 2D ROESY spectrum of $\beta C D-M e l$ at a 2:1 host-guest mole ratio, showing cross-peaks between $\beta C D$ internal $1 \mathrm{H}$ cavity and Mel nuclei. Figure S4. Phase solubility diagram. Figure S5. Cytotoxic efficiency of Melphalan in human malignant melanoma (A375) cell line). A375 cells were seeded at $1 \times 10^{4}$ cells/well in 96-well plate. Toxicity was reported using MTT Assay in comparison with non-treated cells $(100 \%$ viability). $N=3 \pm \mathrm{SD}$.

Author Contributions: Conceptualization, W.M.-S., R.E.V. and I.B.; Methodology, W.M.-S., A.H.K. and L.D.W.; Formal Analysis, W.M.-S., A.H.K. and L.D.W.; Data Curation, W.M.-S. and A.H.K; Writing-Original Draft Preparation, W.M.-S.; Writing-Review \& Editing, A.H.K, R.E.V, L.D.W and IB.; Supervision, R.E.V, L.D.W and I.B Funding Acquisition, L.D.W and I.B.

Funding: This research was funded by The Natural Sciences and Engineering Research Council of Canada grant number 2015-03689. Scholarship W M.-S was provided by Taibah University, Medina 42353, Saudi Arabia.

Conflicts of Interest: The authors declare no conflict of interest.

\section{References}

1. Pilgrim, W.; Hayes, R.; Hanson, D.W.; Zhang, B.; Boudreau, B.; Leonfellner, S. Skin Cancer (Basal Cell Carcinoma, Squamous Cell Carcinoma, and Malignant Melanoma): New Cases, Treatment Practice, and Health Care Costs in New Brunswick, Canada, 2002-2010. J. Cutan. Med. Surg. 2014, 18, 320-331. [CrossRef] [PubMed]

2. WHO. Skin Cancers. WHO, 2016. Available online: http://www.who.int/uv/faq/skincancer/en/index1.html (accessed on 26 February 2018).

3. Edge, S.B.; Compton, C.C. The American Joint Committee on Cancer: The 7th Edition of the AJCC Cancer Staging Manual and the Future of TNM. Ann. Surg. Oncol. 2010, 17, 1471-1474. [CrossRef] [PubMed]

4. Read, R.L.; Haydu, L.; Saw, R.P.; Quinn, M.J.; Shannon, K.; Spillane, A.J.; Thompson, J.F. In-transit melanoma metastases: Incidence, prognosis, and the role of lymphadenectomy. Ann. Surg. Oncol. 2015, 22, 475-481. [CrossRef] [PubMed]

5. Gershenwald, J.E.; Giacco, G.G.; Lee, J.E. Cutaneous Melanoma. In 60 Years of Survival Outcomes at The University of Texas MD Anderson Cancer Center; Springer: Berlin/Heidelberg, Germany, 2013; pp. 153-165.

6. Testori, A.; Verhoef, C.; Kroon, H.M.; Pennacchioli, E.; Faries, M.B.; Eggermont, A.M.; Thompson, J.F. Treatment of melanoma metastases in a limb by isolated limb perfusion and isolated limb infusion. J. Surg. Oncol. 2011, 104, 397-404. [CrossRef] [PubMed]

7. Zar, T.; Graeber, C.; Perazella, M.A. Reviews: Recognition, Treatment, and Prevention of Propylene Glycol Toxicity. Semin. Dial. 2007, 20, 217-219. [CrossRef] [PubMed]

8. Ajazuddin; Alexander, A.; Amarji, B.; Kanaujia, P. Synthesis, characterization and in vitro studies of pegylated melphalan conjugates. Drug Dev. Ind. Pharm. 2013, 39, 1053-1062. [CrossRef]

9. Peyrode, C.; Weber, V.; David, E.; Vidal, A.; Auzeloux, P.; Communal, Y.; Chezal, J.M. Quaternary ammonium-melphalan conjugate for anticancer therapy of chondrosarcoma: In vitro and in vivo preclinical studies. Investig. New Drugs 2012, 30, 1782-1790. [CrossRef]

10. Rajpoot, P.; Bali, V.; Pathak, K. Anticancer efficacy, tissue distribution and blood pharmacokinetics of surface modified nanocarrier containing melphalan. Int. J. Pharm. 2012, 426, 219-230. [CrossRef] 
11. Vodovozova, E.L.; Kuznetsova, N.R.; Kadykov, V.A.; Khutsyan, S.S.; Gaenko, G.P.; Molotkovsky, Y.G. Liposomes as nanocarriers of lipid-conjugated antitumor drugs melphalan and methotrexate. Nanotechnol. Russ. 2008, 3, 228-239. [CrossRef]

12. Cho, K.; Wang, X.; Nie, S.; Chen, Z.; Shin, D.M. Therapeutic Nanoparticles for Drug Delivery in Cancer. Clin. Cancer Res. 2008, 14, 1310-1316. [CrossRef]

13. Tiwari, G.; Tiwari, R.; Sriwastawa, B.; Bhati, L.; Pandey, S.; Pandey, P.; Bannerjee, S.K. Drug delivery systems: An updated review. Int. J. Pharm. Investig. 2012, 2, 2-11. [CrossRef] [PubMed]

14. Challa, R.; Ahuja, A.; Ali, J.; Khar, R.K. Cyclodextrins in drug delivery: An updated review. Aaps Pharmscitech 2005, 6, E329-E357. [CrossRef] [PubMed]

15. Szejtli, J. Introduction and General Overview of Cyclodextrin Chemistry. Chem. Rev. 1998, 98, 1743-1754. [CrossRef] [PubMed]

16. Loftsson, T.; Jarho, P.; Masson, M.; Järvinen, T. Cyclodextrins in drug delivery. Expert Opin. Drug Deliv. 2005, 2, 335-351. [CrossRef] [PubMed]

17. Loftsson, T.; Duchene, D. Cyclodextrins and their pharmaceutical applications. Int. J. Pharm. 2007, 329, 1-11. [CrossRef] [PubMed]

18. Del Valle, E.M. Cyclodextrins and their uses: A review. Process. Biochem. 2004, 39, 1033-1046. [CrossRef]

19. Luke, D.R.; Tomaszewski, K.; Damle, B.; Schlamm, H.T. Review of the basic and clinical pharmacology of sulfobutylether- $\beta$-cyclodextrin (SBECD). J. Pharm. Sci. 2010, 99, 3291-3301. [CrossRef]

20. Zhang, J.; Ma, P.X. Cyclodextrin-based supramolecular systems for drug delivery: Recent progress and future perspective. Adv. Drug Deliv. Rev. 2013, 65, 1215-1233. [CrossRef]

21. Chilajwar, S.V.; Pednekar, P.P.; Jadhav, K.R.; Gupta, G.J.; Kadam, V.J. Cyclodextrin-based nanosponges: A propitious platform for enhancing drug delivery. Expert Opin. Drug Deliv. 2014, 11, 111-120. [CrossRef]

22. Sallas, F.; Darcy, R. Amphiphilic Cyclodextrins-Advances in Synthesis and Supramolecular Chemistry. Eur. J. Org. Chem. 2008, 2008, 957-969. [CrossRef]

23. Quaglia, F.; Ostacolo, L.; Mazzaglia, A.; Villari, V.; Zaccaria, D.; Sciortino, M.T. The intracellular effects of non-ionic amphiphilic cyclodextrin nanoparticles in the delivery of anticancer drugs. Biomaterials 2009, 30, 374-382. [CrossRef] [PubMed]

24. Bilensoy, E.; Hincal, A.A. Recent advances and future directions in amphiphilic cyclodextrin nanoparticles. Expert Opin. Drug Deliv. 2009, 6, 1161-1173. [CrossRef] [PubMed]

25. Cryan, S.; Donohue, R.; Ravoo, B.; Darcy, R.; O’Driscoll, C. Cationic cyclodextrin amphiphiles as gene delivery vectors. J. Drug Deliv. Sci. Technol. 2004, 14, 57-62. [CrossRef]

26. Michel, D.; Chitanda, J.M.; Balogh, R.; Yang, P.; Singh, J.; Das, U.; El-Aneed, A.; Dimmock, J.; Verrall, R.; Badea, I. Design and evaluation of cyclodextrin-based delivery systems to incorporate poorly soluble curcumin analogs for the treatment of melanoma. Eur. J. Pharm. Biopharm. 2012, 81, 548-556. [CrossRef] [PubMed]

27. Poorghorban, M.; Karoyo, A.H.; Grochulski, P.; Verrall, R.E.; Wilson, L.D.; Badea, I. A ${ }^{1} \mathrm{H}$ NMR Study of Host/Guest Supramolecular Complexes of a Curcumin Analogue with $\beta$-Cyclodextrin and a $\beta$-Cyclodextrin-Conjugated Gemini Surfactant. Mol. Pharm. 2015, 12, 2993-3006. [CrossRef] [PubMed]

28. Poorghorban, M.; Das, U.; AlAidi, O.; Chitanda, J.M.; Michel, D.; Dimmock, J.; Verrall, R.; Grochulski, P.; Badea, I. Characterization of the host-guest complex of a curcumin analog with $\beta$-cyclodextrin and $\beta$-cyclodextrin-gemini surfactant and evaluation of its anticancer activity. Int. J. Nanomed. 2015, 10, 503-515.

29. Michel, D.; Mohammed-Saeid, W.; Getson, H.; Roy, C.; Poorghorban, M.; Chitanda, J.M.; Verrall, R.; Badea, I. Evaluation of $\beta$-cyclodextrin-modified gemini surfactant-based delivery systems in melanoma models. Int. J. Nanomed. 2016, 11, 6703-6712. [CrossRef]

30. Donkuru, M.; Chitanda, J.M.; Verrall, R.E.; El-Aneed, A.; El-Aneed, A. Multi-stage tandem mass spectrometric analysis of novel $\beta$-cyclodextrin-substituted and novel bis-pyridinium gemini surfactants designed as nanomedical drug delivery agents. Rapid Commun. Mass Spectrom. 2014, 28, 757-772. [CrossRef] [PubMed]

31. Singh, R.; Bharti, N.; Madan, J.; Hiremath, S. Characterization of cyclodextrin inclusion complexes-A review. J. Pharm. Sci. Technol. 2010, 2, 171-183.

32. Mura, P. Analytical techniques for characterization of cyclodextrin complexes in aqueous solution: A review. J. Pharm. Biomed. Anal. 2014, 101, 238-250. [CrossRef] 
33. Figueiras, A.; Carvalho, R.A.; Ribeiro, L.; Torres-Labandeira, J.J.; Veiga, F.J. Solid-state characterization and dissolution profiles of the inclusion complexes of omeprazole with native and chemically modified $\beta$-cyclodextrin. Eur. J. Pharm. Biopharm. 2007, 67, 531-539. [CrossRef] [PubMed]

34. De Araujo, D.R.; Tsuneda, S.S.; Cereda, C.M.; Carvalho, F.D.G.; Preté, P.S.; Fernandes, S.A.; De F.A. Braga, A. Development and pharmacological evaluation of ropivacaine-2-hydroxypropyl- $\beta$-cyclodextrin inclusion complex. Eur. J. Pharm. Sci. 2008, 33, 60-71. [CrossRef] [PubMed]

35. Neuhaus, D.; Williamson, M.P. The nuclear Overhauser effect in structural and conformational analysis, 2nd ed.; John Wiley \& Sons, Inc.: New York, NY, USA, 2000.

36. Berger, S. One Dimensional and Two Dimensional NMR Spectra by Modern Pulse Techniques. Angew. Chem. 1992, 104, 108-109. [CrossRef]

37. Karoyo, A.H.; Wilson, L.D. Preparation and Characterization of a Polymer-Based "Molecular Accordion". Langmuir 2016, 32, 3066-3078. [CrossRef] [PubMed]

38. Schneider, H.-J.; Hacket, F.; Rüdiger, V.; Ikeda, H. NMR Studies of Cyclodextrins and Cyclodextrin Complexes. Chem. Rev. 1998, 98, 1755-1786. [CrossRef]

39. Wilson, L.D.; Siddall, S.R.; Verrall, R.E. A spectral displacement study of the binding constants of cyclodextrin-hydrocarbon and -fluorocarbon surfactant inclusion complexes. Can. J. Chem. 1997, 75, 927-933. [CrossRef]

40. Bhasikuttan, A.C.; Mohanty, J.; Nau, W.M.; Pal, H. Efficient Fluorescence Enhancement and Cooperative Binding of an Organic Dye in a Supra-biomolecular Host-Protein Assembly. Angew. Chem. 2007, 119, 4198-4200. [CrossRef]

41. Mohammed-Saeid, W.; Michel, D.; Badea, I.; El-Aneed, A.; Mohammed-Saeid, W.; El-Aneed, A. Rapid and Simple Flow Injection Analysis-Tandem Mass Spectrometric (FIA-MS/MS) Method for the Quantification of Melphalan in Lipid-Based Drug Delivery System. Rapid Commun. Mass Spectrom. 2017, 31, 1481-1490. [CrossRef] [PubMed]

42. Higuchi, T.; Connors, A. Phase-solubility techniques. Adv. Anal. Chem. Instrum. 1965, 4, 117-210.

43. Zhengyu, J. Cyclodextrins: Preparation and Application in Industry; World Scientific: Singapore, 2018.

44. Gaumet, M.; Vargas, A.; Gurny, R.; Delie, F. Nanoparticles for drug delivery: The need for precision in reporting particle size parameters. Eur. J. Pharm. Biopharm. 2008, 69, 1-9. [CrossRef] [PubMed]

45. Decuzzi, P.; Godin, B.; Tanaka, T.; Lee, S.-Y.; Chiappini, C.; Liu, X.; Ferrari, M. Size and shape effects in the biodistribution of intravascularly injected particles. J. Control. Release 2010, 141, 320-327. [CrossRef] [PubMed]

46. Dhand, C.; Prabhakaran, M.P.; Beuerman, R.W.; Lakshminarayanan, R.; Dwivedi, N.; Ramakrishna, S. Role of size of drug delivery carriers for pulmonary and intravenous administration with emphasis on cancer therapeutics and lung-targeted drug delivery. Rsc Adv. 2014, 4, 32673-32689. [CrossRef]

47. Gratton, S.E.A.; Ropp, P.A.; Pohlhaus, P.D.; Luft, J.C.; Madden, V.J.; Napier, M.E.; DeSimone, J.M. The effect of particle design on cellular internalization pathways. Proc. Natl. Acad. Sci. USA 2008, 105, 11613-11618. [CrossRef] [PubMed]

48. Fröhlich, E. The role of surface charge in cellular uptake and cytotoxicity of medical nanoparticles. Int. J. Nanomed. 2012, 7, 5577-5591. [CrossRef] [PubMed]

49. Stout, S.A.; Riley, C.M. The hydrolysis of 1-phenylalanine mustard (melphalan). Int. J. Pharm. 1985, 24, 193-208. [CrossRef]

50. Hu, C.-M.J.; Zhang, L. Nanoparticle-based combination therapy toward overcoming drug resistance in cancer. Biochem. Pharm. 2012, 83, 1104-1111. [CrossRef] [PubMed]

(C) 2019 by the authors. Licensee MDPI, Basel, Switzerland. This article is an open access article distributed under the terms and conditions of the Creative Commons Attribution (CC BY) license (http://creativecommons.org/licenses/by/4.0/). 